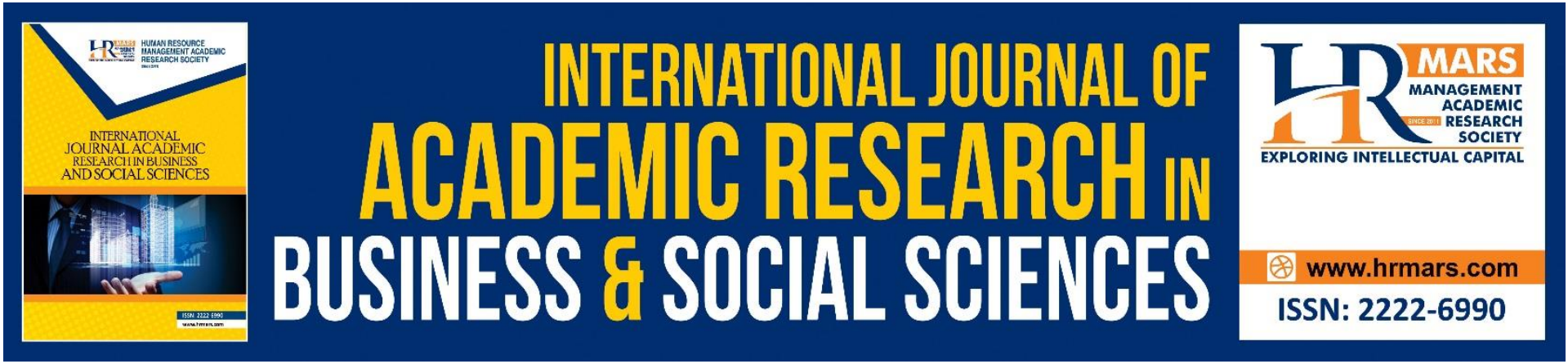

\title{
Investigation and Analysis on the Current Situation of College Sport Accident - A Case Sutdy of Shaanxi China
}

\author{
Liu Bin, Jaffry Zakaria
}

To Link this Article: http://dx.doi.org/10.6007/IJARBSS/v10-i12/8051

DOI:10.6007/IJARBSS/v10-i12/8051

Received: 10 October 2020, Revised: 09 November 2020, Accepted: 20 November 2020

Published Online: 09 December 2020

In-Text Citation: (Bin \& Zakaria, 2020)

To Cite this Article: Bin, L., \& Zakaria, J. (2020). Investigation and Analysis on the Current Situation of College Sport Accident - A Case Sutdy of Shaanxi China. International Journal of Academic Research in Business and Social Sciences, 10(12), 234-246.

\section{Copyright: (c) 2020 The Author(s)}

Published by Human Resource Management Academic Research Society (www.hrmars.com)

This article is published under the Creative Commons Attribution (CC BY 4.0) license. Anyone may reproduce, distribute, translate and create derivative works of this article (for both commercial and non-commercial purposes), subject to full attribution to the original publication and authors. The full terms of this license may be seen at: http://creativecommons.org/licences/by/4.0/legalcode

\section{Vol. 10, No. 12, 2020, Pg. $234-246$}

Full Terms \& Conditions of access and use can be found at http://hrmars.com/index.php/pages/detail/publication-ethics 


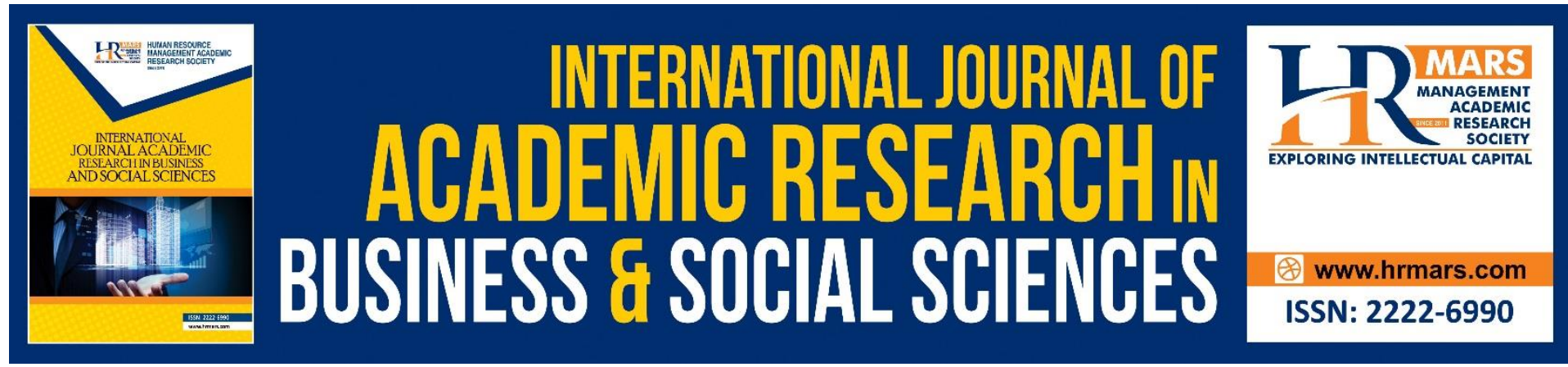

\title{
Investigation and Analysis on the Current Situation of College Sport Accident - A Case Sutdy of Shaanxi China
}

\author{
Liu Bin ${ }^{1,2}$, Jaffry Zakaria ${ }^{1}$ \\ ${ }^{1}$ Faculty of Sport Science and Coaching, Universiti Pendidikan Sultan Idris; Tanjong Malim, \\ Malaysia, ${ }^{2}$ Faculty of Physical Education, Baoji University of Arts and Sciences; Baoji, China. \\ Email: lifego.bin@163.com
}

\begin{abstract}
The contradiction between the objective existence of college sports safety accidents and the development needs of school sports has become an obstacle to the healthy development of college sports. This paper presents the investigation of 200 sport college teachers of Shaanxi China to know the current situation of college sport accident by the mean of questionnaire and interviewing some respondents on related issues. Through analyzing the existing problems and the investigation results gives some comments and suggestions. The aim of this study is to avoid or reduce the occurrence of school sports accidents and provide reference for the establishment of school sports safety accident prevention system.
\end{abstract}

Keywords: College Sport, Sport Accident, Sport Injury, Status, Shaanxi China

\section{Introduction}

College is the best time to perfect and solidify students' awareness of lifelong physical training, and it is also the key period for students' overall physical and mental development (Bo, 2010; Pascarella \& Terenzini, 2005). However, in colleges, accidental injuries and even deaths have occurred frequently in sports activities in recent years. In order to avoid the risk of students' exercise, some colleges and universities have stopped heavy sports activities, and the idea of absolutely safe physical education has gradually prevailed. The low-load absolutely safe physical education model cannot meet the needs of school physical education to enhance students' physical fitness (Knapik, Harman, Steelman \& Graham, 2012; Zhang \& Li, 2008). The contradiction between the objective existence of college sports safety accidents and the development needs of school sports has become an obstacle to the healthy development of college sports. The establishment of sports accident prevention system in colleges and universities is an urgent requirement to ensure the scientific and effective development of sports in colleges and universities, the active and safe participation of students in sports, and the enhancement of students' physical fitness (Wang, Li, \& Lei, 2016; Agent, Stamatiadis \& Jones, 1996). This study investigates and analyzes the current situation of sports accidents in colleges and universities in Shaanxi province of China, aiming at avoiding 
or reducing the occurrence of sports accidents in schools, and providing reference for the establishment of school sports safety accident prevention system.

\section{Problem Statement}

School sports injury accidents have become a big problem that troubles the development of school sports work. Only through in-depth investigation and analysis of the current situation and causes of school sports injury accidents can we make targeted solutions to the problems. Through reading the literature, researcher found that there were few investigations and analyses on the regional sports injury accidents in colleges and universities, and there was no investigation on the current situation of sports injury accidents in colleges and universities in Shaanxi Province. Therefore, the author discussed and analyzed the following questions. What is the present situation of sports injury accidents in Colleges and universities in Shaanxi province? What are the causes of sports accidents in Colleges and universities in Shaanxi Province? What kind of mechanism to prevent sports injury accidents can provide better help for reducing sports injury accidents in Colleges and universities in Shaanxi province?

\section{Literature Review}

\section{Safety Education of School Sports}

School physical education can promote the healthy development of people, and the responsibility of school physical education is the health of students. Li and Liang (2015) proposed to integrate life safety education with physical education and establish the guiding ideology of "safety first". It is suggested that PE teachers should teach students basic escape skills and defense knowledge (Li \& Liang, 2015; Darwish et al., 2018). Liu (2019) conducted a case study of safety education in orienteering. They believe that many schools' emergency safety education is affected by ideology, concepts, resources and other factors, and there are phenomena such as marginalization, single content, and difficulty in carrying out safety education. Absence and low efficiency are the crux of current emergency safety education for young people (Liu, 2019). Researchers such as Liu and Wang (2015), Sun (2015), Sun (2016), Shi (2016) and so on have analyzed school safety education from different perspectives. The above-mentioned researchers' research on the theories and concepts of school sports safety education mainly focuses on the description of the phenomenon, and there are few case studies, but they all urgently call for attention to the safety of sports teaching.

\section{Sports Safety Accidents in Colleges and Universities}

Some sports injuries have also occurred in colleges and universities, and these problems have affected normal teaching. Scholars have conducted research and discussion on this. Song (2016) explained that sudden deaths in sports activities in colleges and universities mainly occur in physical education classes, physical testing, competition activities, amateur activities, and school military training. The occurrence of sports safety accidents is uncertain, sudden, complex, and Diversity, severity of consequences, and widespread impact. The accident factors mainly include heredity, season, management, psychology and other accidental factors, and each factor is interrelated and affects each other. The author called for the construction of a corresponding defense mechanism through analysis and feedback on the causes of sudden deaths in sports activities in colleges and universities to protect the lives of students (Song, 2016). Yin (2017) argued in "Talking about the Importance of Safety Education in Physical Education in Colleges and Universities" that the diversification of school sports space and the increase in sports population have led to more sports injuries and call 
on colleges and universities to establish a sports safety management mechanism to effectively ensure campus safety and harmony (Yin, 2017). Jiang (2015) stated that college students' sports safety is not only a school education issue, but also a social education issue. We should unite the whole society to mobilize and protect together, and propose to build a protection system with schools, families, and teachers. Student sports injury accidents not only bring misfortune and pain to the victims and their families, but also cause confusion and uneasiness in the education administration department and schools. Therefore, college sports injury accidents have become a topic worthy of attention and research.

\section{Methodology}

After reviewing the relevant literature and soliciting the opinions of 2 professors and 1 associate professor, this research developed a survey questionnaire on the status of sports safety accidents in colleges and universities in Shaanxi Province. Then, 4 professors and 3 associate professors from 3 universities evaluated the validity of the questionnaire. Experts believe that the questionnaire can effectively investigate the status of sports safety accidents in colleges and universities, and can be used to investigate and analyze related issues. After that, a survey on the reliability of the questionnaire was conducted by 20 college teachers, and the results showed that the questionnaire was reliable. Finally, 200 physical education teachers from 10 colleges and universities in Shaanxi Province were selected as the survey subjects, and the current situation of sports safety accidents in relevant colleges and universities during the three years from 2017 to 2019 was investigated through online questionnaires. 192 questionnaires were collected, and the effective rate was $100 \%$.

\section{Results and Analysis}

\section{Current Situation of School Sports Safety Accidents Frequency of School Sports Safety Accidents}

A questionnaire survey of sports safety accidents in 10 colleges and universities in Shaanxi province over the past 3 years found that among the total 152 accidents, there were 43 cases (28.3\%) in 2017, 53 cases (34.9\%) in 2018, and 56 cases (36.8\%) in 2019, as shown in the figure 1 below.

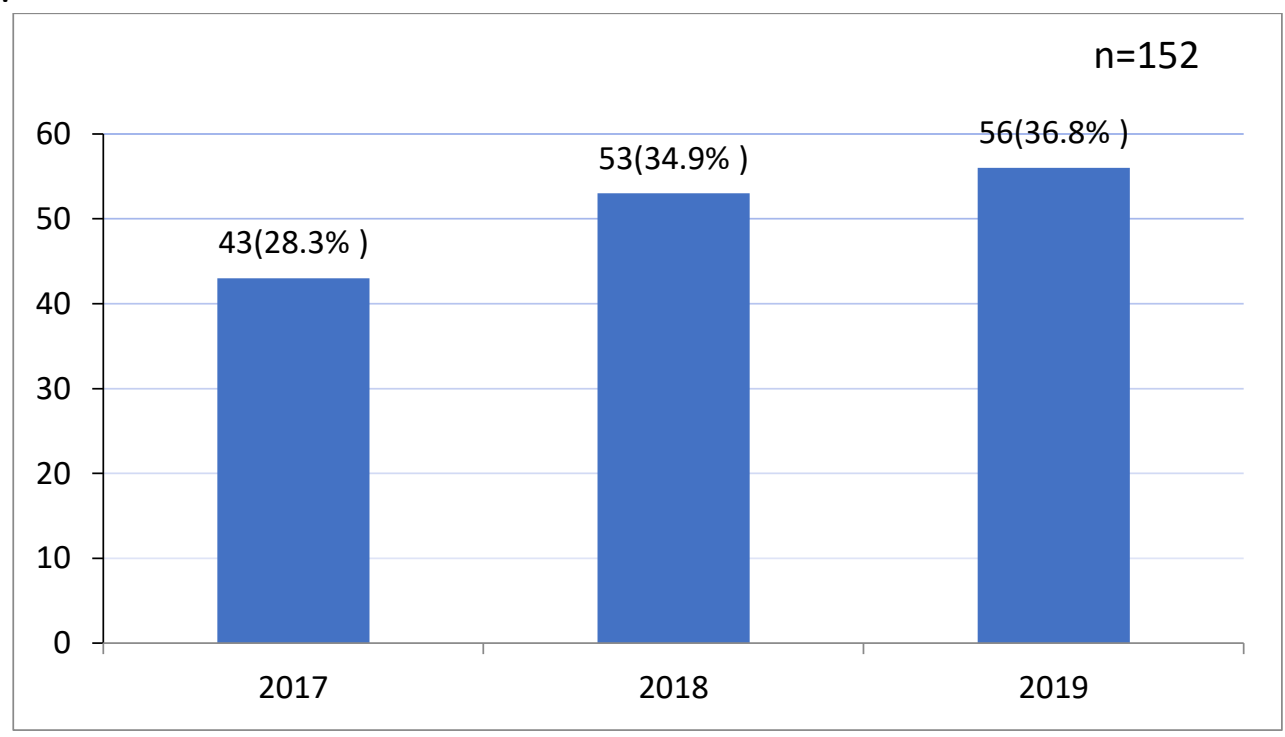

Figure 1 Frequency of School Sports Safety Accidents in Recent Three Years ( $n=152)$ 
It can be seen that school sports safety accidents are on the rise year by year. The reasons for the increasing frequency year by year are as follows: on the one hand, the total amount of school sports activities is increasing, the country, schools, families and individuals pay more and more attention to sports, and the increase of sports activities inevitably leads to the increase of sports safety accidents. On the other hand, the increase of obesity rate and the decline of physical function and quality have gradually become the main characteristics of the physical changes of college students, laying hidden dangers for the occurrence of sports safety accidents (Islam \& Debnath,2020; Craven \& Fekete, 2019; Zhang \& Hua, 2016; Li, 2002). In addition, due to the school sports safety accident system is not perfect, the site equipment is not standard, the education intervention is not enough, the skill training is insufficient, the medical supervision is not in place, as well as the teacher and the student safety consciousness is weak and so on, various subjective and objective factors have caused the student sports safety accident to rise year by year.

\section{Periods of School Sports Safety Accident}

School sports safety accidents which a student is physically harmed, resulting in his injury, disability or death include occurring in physical education classroom teaching, sports competitions, sports team training, and physical safety accidents occurring in extracurricular sports activities (Weng \& Peng, 2009). The survey results showed that the most safety accidents occurred in physical education classroom teaching, with 64 cases (42.1\%), followed by extracurricular sports activities, 48 cases (31.6\%), sports competitions organized by schools, 28 cases (18.4\%). Sports safety accidents occurred in sports team training is the least, with 12 cases (7.9\%). As figure 2 shows below.

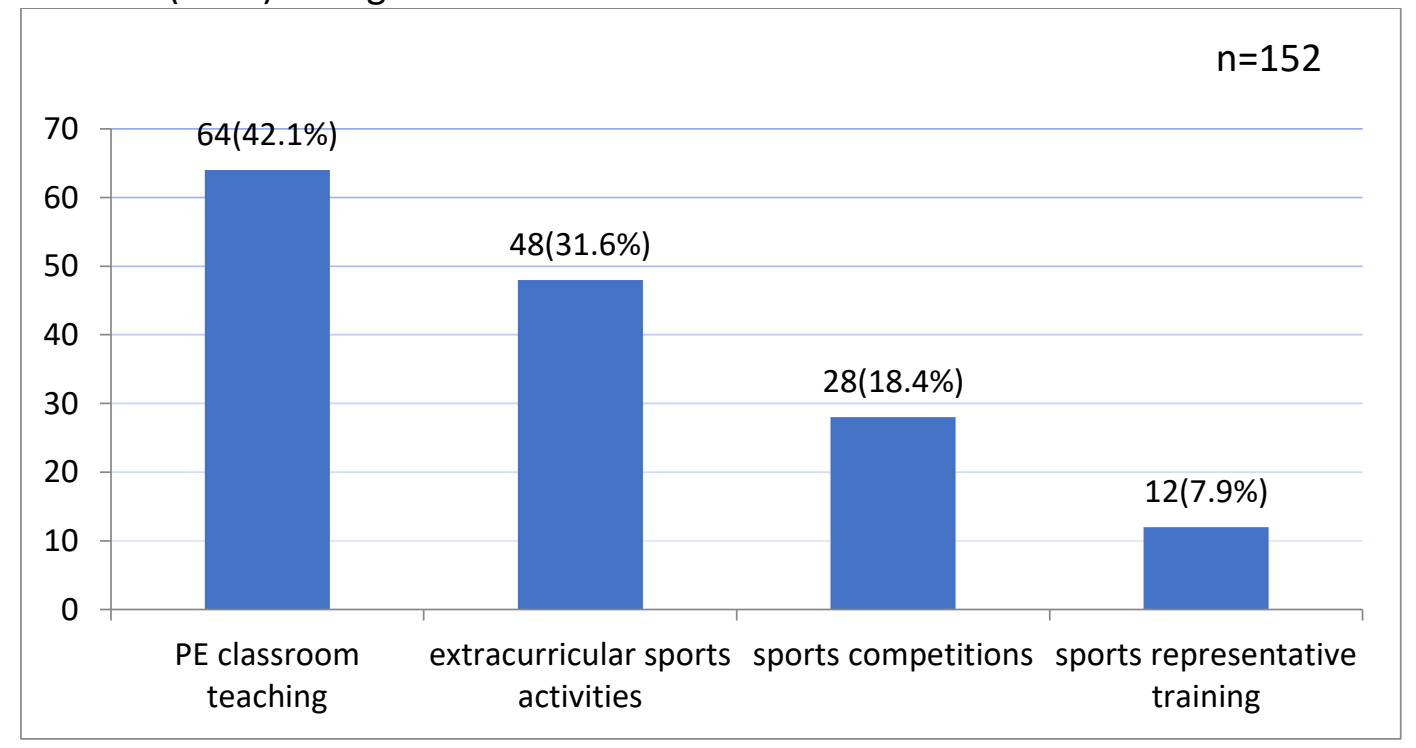

Figure 2 Periods of School Sports Safety Accident $(n=152)$

\section{Sport Types of School Safety Accidents}

Statistics show (FIG. 3) that the probability of school sports injury accidents caused by samefield confrontation sports is the highest, followed by track and field sports, gymnastics and net-isolation confrontation sports are lower. 


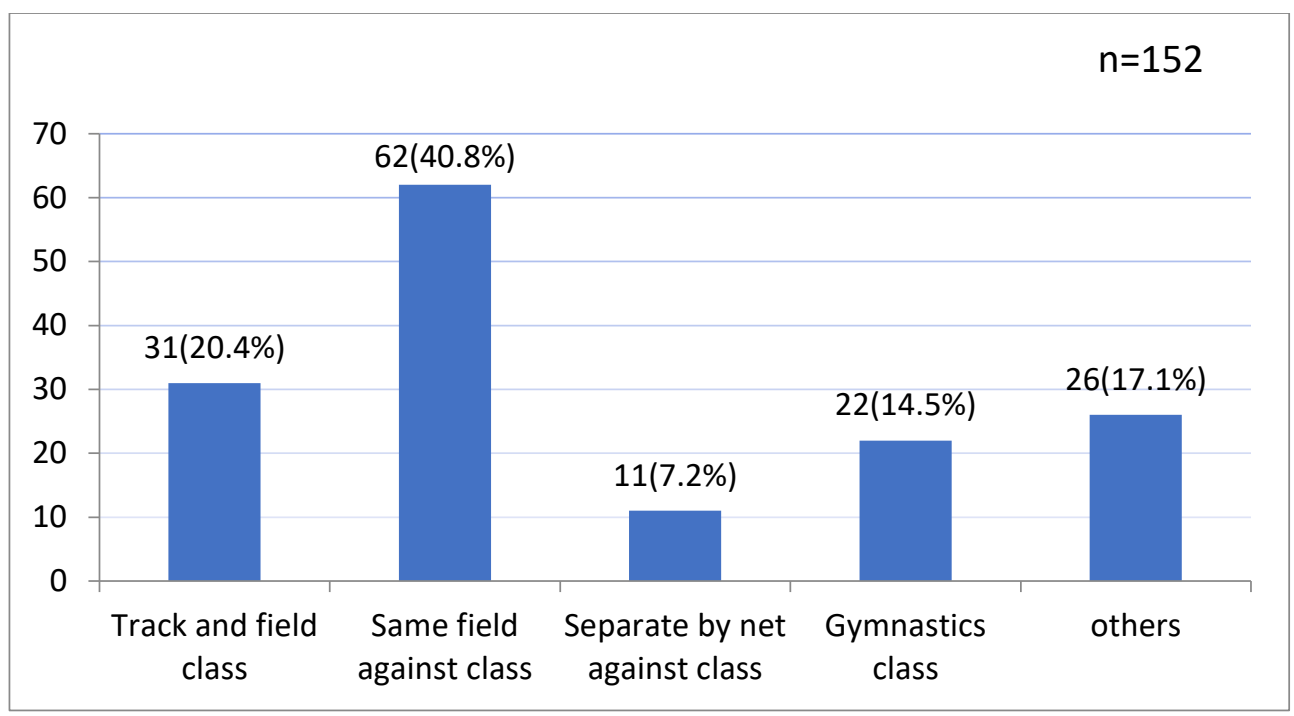

Figure 3 Sport Types of School Safety Accidents ( $n=152)$

The specific reasons are related to the characteristics of various sports events and students' own control over sports skills and risk perception. According to statistics, the number of sports injuries caused by basketball and football in the same field of competition are 33 and 29 respectively. It can be seen that the same-field confrontation projects carried out by schools are mostly football and basketball with strong physical antagonism and fast pace of offensive and defensive transitions. Without professional training and poor selfprotection ability become the inducement of injury accidents (Yan, 2017). As a general sport without physical contact, track and field sports have a high probability of causing accidents, which may be related to ineffective supervision of teachers, unreasonable design of curriculum content, and unclear understanding of students' physical conditions. The reason of the low accident probability of gymnastics events is related to the technical difficulty and sports risk of gymnastics events. The reason for the low accident probability of the networkisolation antagonistic projects is that the students have less physical contact opportunities and relatively low risk coefficient when doing the net-isolation exercises.

\section{Injury Accident Types and Frequency of School Sports}

According to the investigation, the main types of school sports injuries are: fracture, sprain, dislocation, abrasions, shock and death. There were 42 fracture accidents (27.6\%), 46 sprain accidents (30.3\%), 22 dislocation accidents (14.5\%), 31 abrasions (20.4\%), 6 shock accidents (3.9\%) and 5 deaths (3.3\%) in the surveyed universities (FIG.4). 


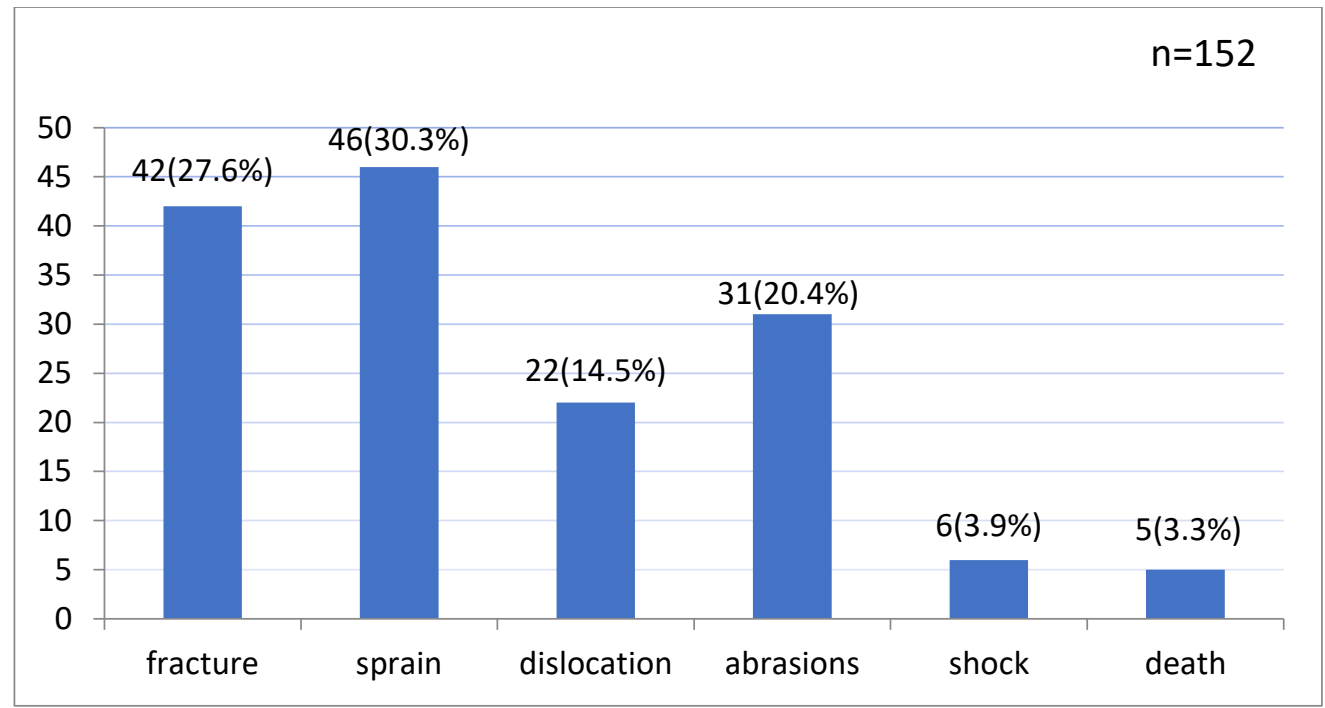

Figure 4 Injury Accident Types and Frequency of School Sports ( $n=152)$

The causes of various sports injuries are mainly caused by various comprehensive factors, such as students' insufficient awareness of sports protection, overconfidence and carelessness, poor physical quality, incorrect technical movements, lack of self-protection ability, and not doing preparatory activities before sports. According to the statistics, the death rate of those who had been injured reached 3.3 percent, while the rate of fracture and sprain reached 57.9 percent. Although these data cannot reflect all the sports injury accidents in colleges and universities, we must attach great importance to the safety work of school sports and strictly control the sports risk. If the occurrence of sports injury accidents in schools cannot be effectively prevented and controlled, PE teachers will reduce the quality of curriculum for fear of sports injury accidents, thus affecting the development of school sports work.

\section{Causes of Sports Safety Accidents in Colleges}

\section{School Sports Safety Education Intervention and Skills Training}

According to the survey of school physical education safety education, $78.2 \%$ (150) of the teachers often provide safety education to students, $15.6 \%(30)$ of the teachers occasionally provide safety education to students, and few teachers do not provide physical education safety education to students (Table 1).

Table 1 Frequency of Teachers' Safety Education to Students $(\mathrm{N}=192)$

\begin{tabular}{|c|c|c|c|c|}
\hline Items Frequency & Always & Often & Occasionally & Seldom \\
\hline Amount & 22 & 128 & 30 & 12 \\
\hline Proportion & $11.5 \%$ & $66.7 \%$ & $15.6 \%$ & $6.1 \%$ \\
\hline
\end{tabular}

In the investigation of whether the selected schools have formulated the "Safety Standards for School Physical Education", 8 colleges and universities have not formulated the "Safety Standards for School Physical Education", 9 colleges and universities have no special sports accident safety training materials, and 8 colleges have not trained their students in sports safety skills, and nearly two-thirds of physical education teachers have not participated in first aid training. It can be seen that the importance of university leaders on sports safety 
education needs to be improved, and safety education in sports activities has not been implemented in most universities.

\section{Hidden Dangers Exist in the Standardization and Safety of School Sports Facilities}

Unsafe sports facilities such as venues and equipment are indirect factors that cause sports safety accidents (Liu \& Zhu, 2013). 29.2\% (56) of the respondents believe that the layout of school sports equipment is very reasonable, $46.4 \%(89)$ of the respondents believe that the layout of school sports equipment is basically reasonable, and $24.5 \%$ (47) of the respondents believe that the layout of school sports equipment is unreasonable (Figure 5). 11.5\% (22) of the respondents believe that the school sports venues fully meet the teaching needs, $45.8 \%$ (88) of the respondents believe that the school sports venues basically meet the teaching needs, and $42.7 \%(82)$ of the respondents believe that the school sports venues cannot meet the teaching needs teaching needs (Figure 6), among them, 36.5\% (70) think that there are problems with the quality of equipment. Of the 10 sampled universities, 3 schools did not conduct safety inspections on sports equipment, 4 schools inspected once a year, and 3 schools inspected once every semester (Figure 7).

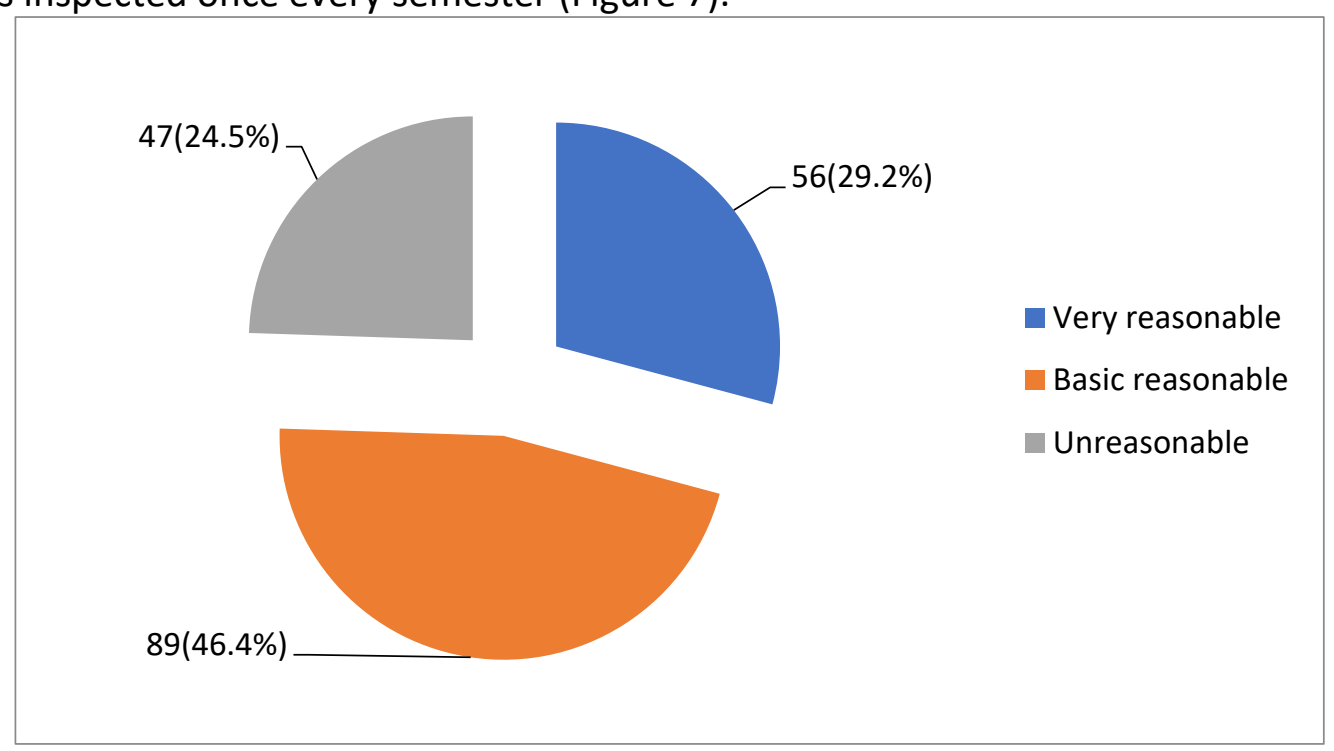

Figure 5 Teachers' Investigation on the Reasonableness of School Sports Equipment Arrangement $(\mathrm{N}=192)$

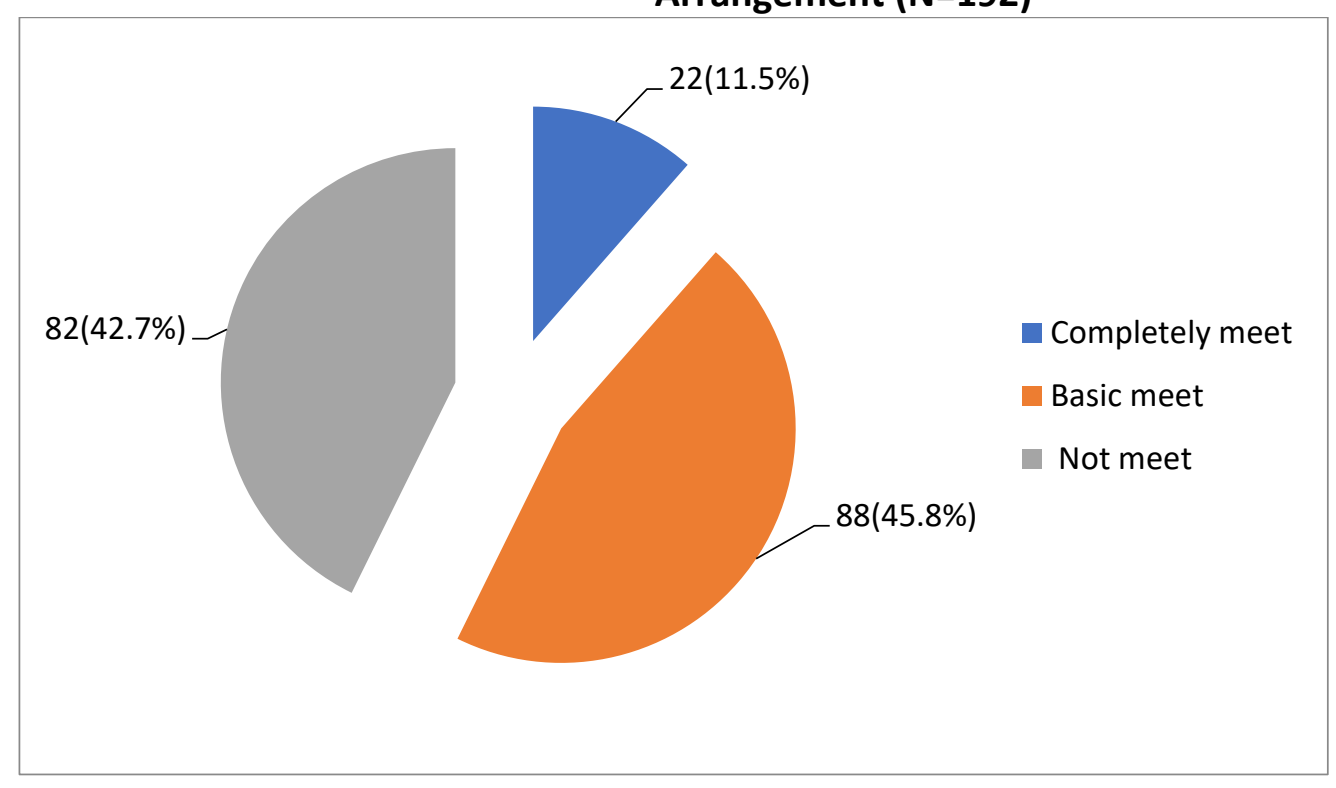


Figure 6 Teachers' Investigation on Whether School Sports Venues Meet Teaching Needs $(\mathrm{N}=192)$

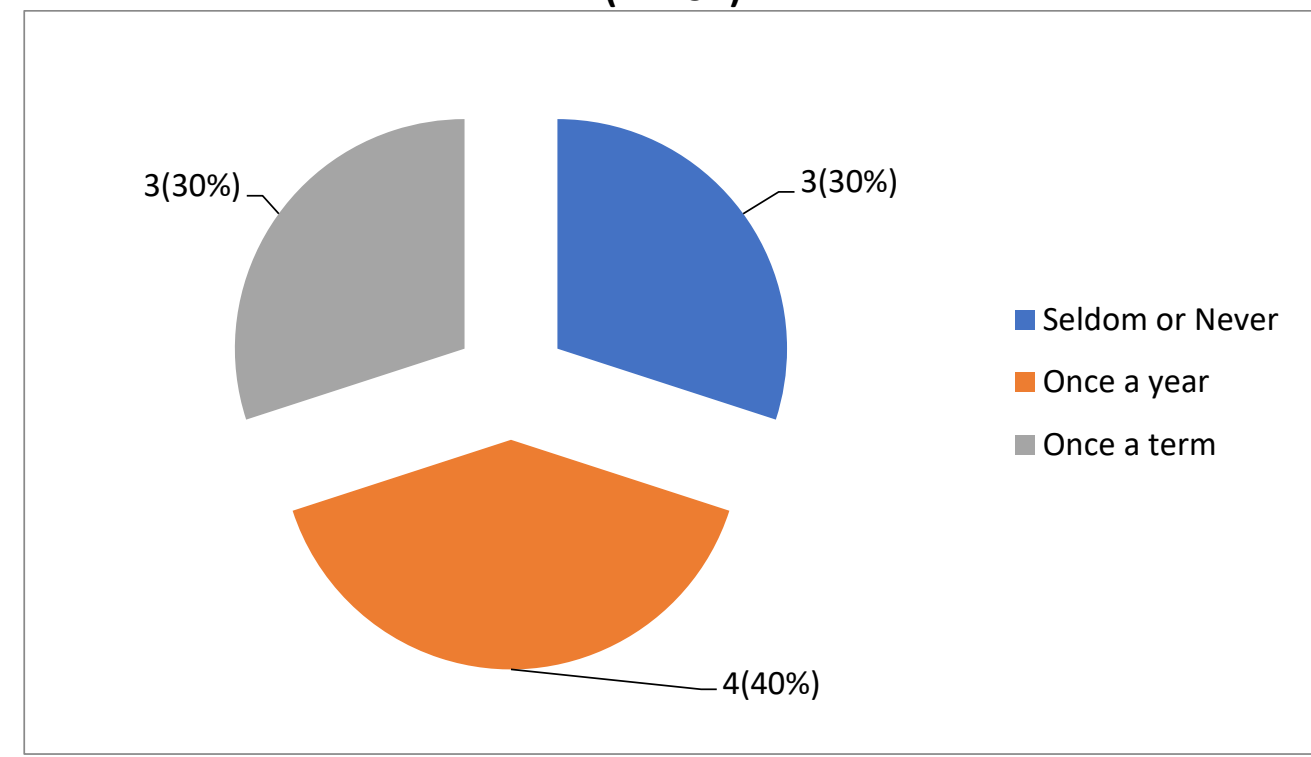

Figure 7 Investigation on the Safety Inspection of Sports Facilities by Schools ( $N=192)$

\section{Physical deterioration of students}

The decline of students' physical fitness is an important cause of school sports safety accidents (Peng, Yang \& Yan, 2020). The survey showed that $44.1 \%$ (67) of the students who had experienced sports safety accidents were overweight, $20.4 \%$ (31) were fat, and $35.5 \%$ (54) were thin (Figure 8).

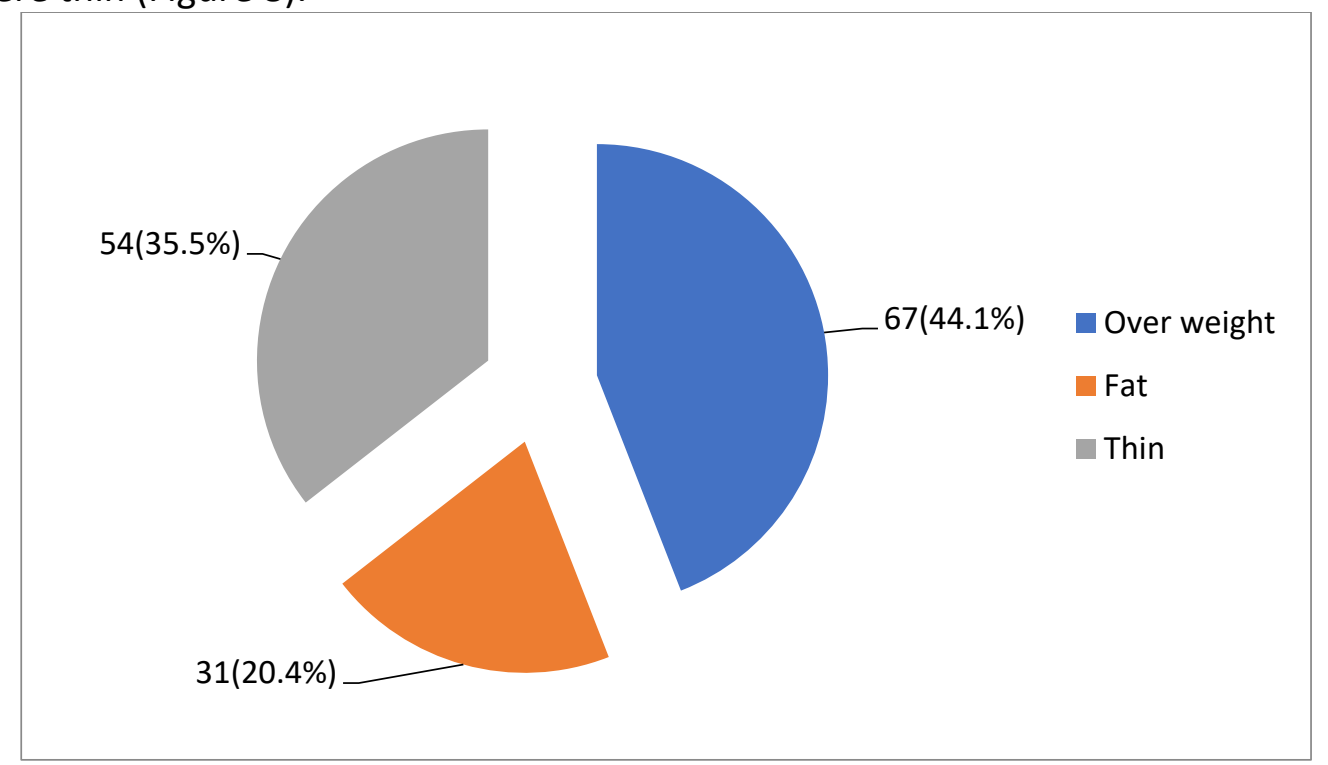

\section{Figure 8 Investigation on the Physical Condition of Students Who have had Safety Accidents ( $\mathrm{N}=192)$}

This is also an important factor that leads to students' relatively poor endurance, strength, agility, balance ability, coordination, etc., which brings difficulties to the completion of teaching tasks, resulting in injury accidents due to the inability to bear the corresponding load when doing movements. In this case, the schools have to avoid all possible risks. The "safety first" physical education class fails to achieve the purpose of enhancing students' physical fitness in terms of content, time, intensity, and load. This vicious circle hinders school sports to promote the physical health of college students. 


\section{The School Sports Medical Supervision System}

Through the investigation, it is found that the status of physical education medical supervision in colleges and universities in Shaanxi Province is not good. For large-scale sports events, professional competitions, and the annual physical fitness test of college students, the school medical staff only conducts precaution in competition for students, and rarely conducts physical fitness assessments of participating athletes before the competition. Therefore, the medical supervision system for school sports needs to be further improved.

\section{Conclusion}

Through the above investigation and analysis, we can see the status of sports safety accidents in colleges and universities in Shaanxi Province: the incidence of sports safety accidents is increasing year by year; the periods of school sports safety accidents is the most prone to safety accidents in sports classroom teaching, followed by extracurricular sports activities and in sports competitions organized by schools, there are relatively few safety accidents in sports team training; school sports safety accidents are characterized by the type of sports: the same field confrontation sports cause the highest probability of school sports injury accidents, followed by track and field events, gymnastics. The probability of accidents caused by network-isolation confrontation exercises is low; the main types of school sports injuries are: fractures, sprains, dislocations, abrasions, shock, and death.

\section{Recommendation}

In order to avoid or reduce the occurrence of school sports safety accidents, it is an important and urgent task to establish school sports safety accident prevention system that integrates system construction, education intervention, skills training, medical supervision, and emergency warning (Figure 9). 


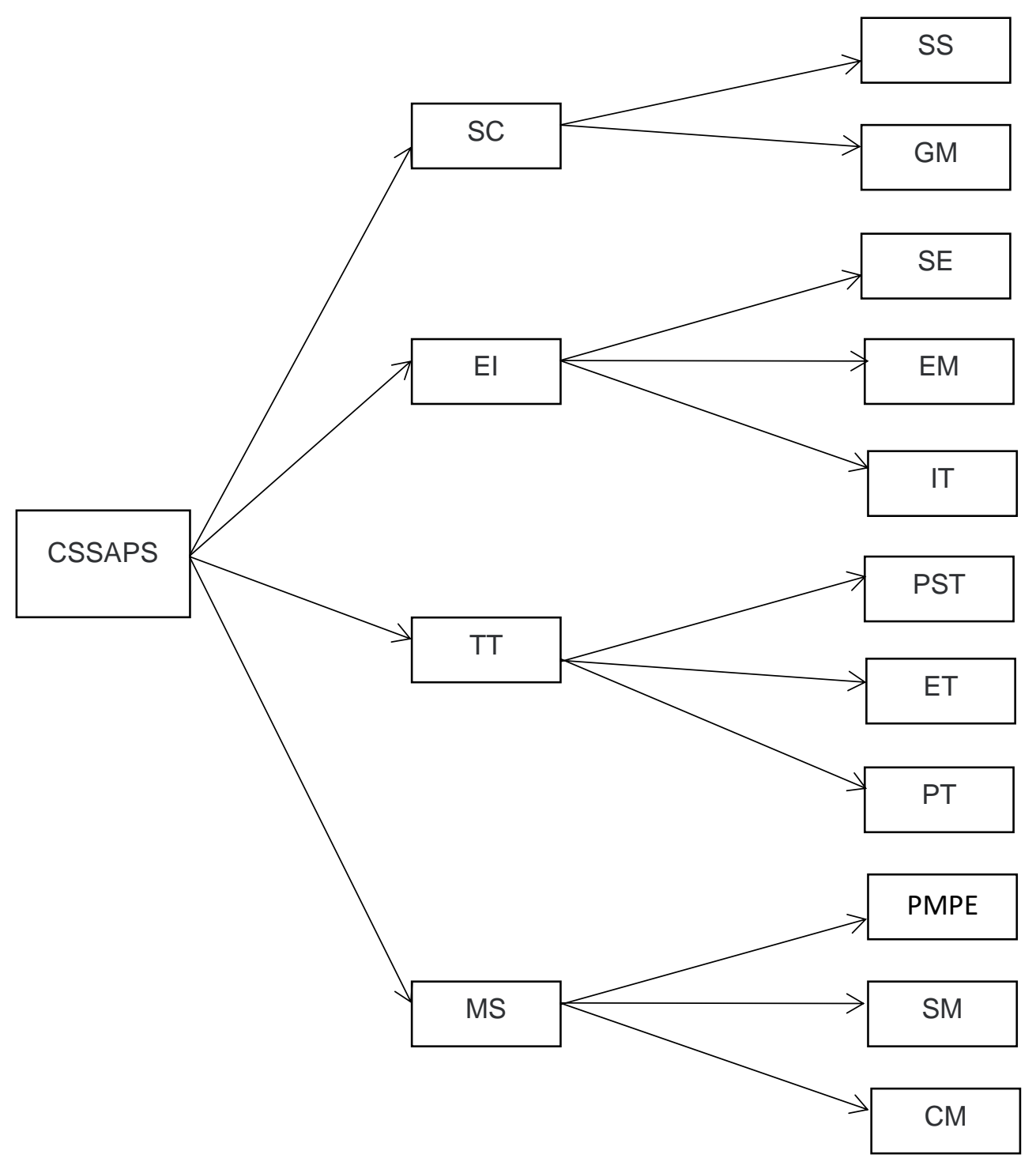

Figure 9 College Sports Safety Accident Prevention System (CSSAPS)

Note, $\mathrm{SC}=$ System Construction; El= Educational Intervention; $\mathrm{TT}=$ Technical Training; MS =Medical Supervision; SS =Safety Standards; GM= Guarantee Mechanism; IT= Individualized Teaching; SE =Safety Education; EM= Equipment Maintenance; PST= Protection Skills Training; ET=Emergency Treatment; PT=Physical Training; PMPE= Pre-match Physical Examination; $\mathrm{SM}=$ Supervision in the Match; $\mathrm{CM}=$ Consultation after the Match.

Strengthen the management responsibilities of schools and teachers. The scope of educational intervention for teachers and schools should include: teachers provide safety education to students through various lectures, broadcasts, networks, etc.; master students' physical and health conditions, and teach students in accordance with their aptitude; prevent possible safety accidents, and in teaching, training, school facilities and equipment maintenance and other aspects take appropriate measures to manage student activities; emergency treatment measures can be provided in time after an accident occurs. Schools should be equipped with qualified and safe sports facilities and equipment, and they should be maintained regularly. 
The target of skill training includes teachers and students. The training content should include familiarity with the technical essentials, precautions and dangers of sports movements; master the protection methods and skills of various technical movements; understand medical knowledge, first aid skills, and sports injury handling procedures, in order to take scientific emergency measures when sport injury accidents happen.

Medical supervision should include: Pre-match Physical Examination (PMPE), Supervision in the Match (SM) and Consultation after the Match (CM). So as to immediately understand the physical condition of students, effectively prevent the occurrence of sports safety accidents.

\section{Acknowledgement}

This paper was supported by research program funded by project of the Baoji University of Arts and Sciences (No. ZK2017067).

\section{References}

Bo, W. (2010). The Unfinished Transformation -- Talent Cultivation and Student Development of Capital Higher Education in the Popularization Stage. Education review of Peking University, 8(01), 27-44+189.

Craven, M. P., \& Fekete, E. M. (2019). Weight-related shame and guilt, intuitive eating, and binge eating in female college students. Eating behaviors, 33, 44-48.

Islam, M. A., \& Debnath, C. R. (2020). Frequency of Dysglycemia and Obesity among Undergraduate Students of a Medical College of Bangladesh. Mymensingh Med J, 29(3), 539-544.

Darwish, S., Abdo, H., \& AlShuwaiee, W. M. (2018). Opportunities, challenges and risks of transition into renewable energy: the case of the Arab Gulf Cooperation Council. International Energy Journal, 18(4).

Jiang, R. (2015). Analysis and Prevention of Safety Hidden Dangers in Physical Education. Technology and Education, (1). 3-9.

Knapik, J. J., Harman, E. A., Steelman, R. A., \& Graham, B. S. (2012). A systematic review of the effects of physical training on load carriage performance. The Journal of Strength \& Conditioning Research, 26(2), 585-597.

Liu, D., \& WANG, H. Zh. (2010). Safety precautions and Research Strategies in Physical Education teaching in colleges and Universities. Journal of Beijing Sport University, (3). 23-27.

Li, H. B., \& Liang, J. Q. (2014). The Construction Gist of physical Education Curriculum in Primary and Secondary Schools with Embedded Life Safety Education content. China After-School Education, 11, 155-158.

$\mathrm{Li}, \mathrm{J}$. (2002). Study on the influence of obesity on the physical quality of college students [J]. Journal of Beijing Sport University, (04), 484-486.

Liu, J. K., \& Zhu, G. L. (2013). Comprehensive evaluation of classroom teaching safety ability of physical education teachers. Journal of Shanghai institute of physical education, 37(03), 89-94.

Liu, K., \& Liu, M. (2019). Current Situation and Development Countermeasure of Outdoor Leisure Sports Tourism for College Students in Zhuhai City. In 1st International Conference on Business, Economics, Management Science (BEMS 2019). Atlantis Press. 
Liu, Y., \& Liu, W. J. (2019). Research on the Integration Model of experiential teaching of orienteing and Emergency Safety Education. Journal of Capital Institute of Physical Education, (3). 23-27.

Ou, Z. (2020). Discussion on Safety Risk Factors and Management of College Physical Education. In 2020 International Conference on Urban Engineering and Management Science (ICUEMS) (pp. 657-660). IEEE.

Pascarella, E. T., \& Terenzini, P. T. (2005). How College Affects Students: A Third Decade of Research. Volume 2. Jossey-Bass, An Imprint of Wiley. 10475 Crosspoint Blvd, Indianapolis, IN 46256.

Peng, Y. L., Yang, J., \& Yan, J. H. (2020). Current status of college students' lifestyle and physical health at home and abroad. Chinese school health, 41(10), 1583-1587.

Song, G. Ch. (2016). Causes of Sudden Sports Death in college Sports activities and construction of Defense Mechanism. Guide to Sports Culture, (3). 34-38.

Sun, R. H. (2015). Investigation, Analysis and Prevention of College Students' Sports Injury accidents. Sichuan Sports Science, 6:3-7.

Wenjia, C. H. E. N. (2020). The Reflection and Countermeasures of University Sports Injury Accident. Canadian Social Science, 16(2), 34-42.

Weng, R., \& Peng, Y. (2009). Legal Liability analysis of School Physical Education Safety Accidents. Contemporary Education Theory and Practice, 1(1), 15-17.

Wang, G., Li, Z. J., \& Lei, X. H. (2016). The Goal of school sports: "Healthy"? "Strong"?. Journal of physical education, 23(03), 9-15.

Yan J. H. (2017). Study on characteristics, legal liability, and risk Prevention and Control measures of school sports Injury accidents -- Based on a meta-analysis of 58 judgment documents. Journal of chengdu institute of physical education, 43 (5), 13 19.

Yin, P. H. (2017). On the importance of safety Education in physical Education in Colleges and universities. Journal of Beijing Sport University, (3). 23-27.

Zhang, J., \& Hua, L. (2016). Obesity status of students in a university and health education countermeasures. Chinese school medicine, 30(01), 30+33.

Zhang Q. W., \& Li X. Q. (2008). Inquiry into and Analysis of Successful Experience of Application of "the Principle That Training Should Be Hard, Strict, Geared to Needs of Actual Combat and with Heavy Load" to Training Practice. Journal of Shanghai institute of physical education, 32(06), 70-72. 